\title{
Expanding Genetic and Functional Diagnoses of IGF1R Haploinsufficiencies
}

\author{
Paula Ocaranza $^{a}$ Marjorie C. Golekoh ${ }^{b}$ Shayne F. Andrew ${ }^{c}$ Michael H. Guo ${ }^{d}$ \\ Paul Kaplowitz ${ }^{\mathrm{e}}$ Howard Saal $^{\mathrm{f}}$ Ron G. Rosenfeld ${ }^{\mathrm{g}}$ Andrew Dauber $^{\mathrm{c}}$ \\ Fernando Cassorla ${ }^{a}$ Philippe F. Backeljauw ${ }^{c}$ Vivian $\mathrm{Hwa}^{c}$ \\ ${ }^{a}$ Institute of Maternal and Child Research, School of Medicine, University of Chile, Santiago, Chile; \\ ${ }^{b}$ Pediatric Endocrinology, Children's Hospital of Michigan, Detroit, MI, USA; ${ }^{C}$ Cincinnati Center for Growth Disorders, \\ Division of Endocrinology, Cincinnati Children's Hospital Medical Center, Cincinnati, OH, USA; d Division of \\ Endocrinology, Boston Children's Hospital and Department of Genetics, Harvard Medical School, Boston, MA, USA; \\ e Division of Pediatric Endocrinology and Diabetes, Children's National Health System, Washington, DC, USA; \\ fDivision of Human Genetics, Cincinnati Children's Hospital Medical Center, Cincinnati, OH, USA; 9 Department of \\ Pediatrics, Oregon Health \& Science University, Portland, OR, USA
}

\section{Established Facts}

- Copy number variations (CNV) involving the insulin-like growth factor 1 receptor gene (IGF1R) result in varying degrees of pre- and postnatal growth restriction.

\section{Novel Insights}

- CNV discovery based on whole exome sequencing (WES) expands the spectrum of information that can be derived from analysis of WES: out of $27 \mathrm{CNV}$ uncovered, a 4.492-Mb de novo CNV encompassing IGF1R was identified.

- Allelic IGF1R haploinsufficiency translated to a reproducible 50\% decrease in cell-surface IGF1R protein availability when primary cells from patients were analyzed by fluorescence-activated cell sorting (FACS), thus providing functional evidence for the critical importance of biallelic protein expression.

- FACS analysis of live primary cells is a promising method to efficiently evaluate and screen for IGF1R haploinsufficiency.

\section{Keywords}

Short stature - IGF1R copy number variants - Whole exome sequencing $\cdot$ FACS analysis

P. Ocaranza, M.C. Golekoh, S.F. Andrew, and M.H. Guo are co-first authors.

\begin{abstract}
Background: The growth-promoting effects of IGF-I is mediated through the IGF-I receptor (IGF1R), a widely expressed cell-surface tyrosine kinase receptor. IGFIR copy number variants (CNV) can cause pre- and postnatal growth restriction or overgrowth. Methods: Whole exome sequence (WES), chromosomal microarray, and targeted IGF1R gene analyses
\end{abstract}

\section{KARGER}

(C) 2017 S. Karger AG, Basel

E-Mail karger@karger.com

www.karger.com/hrp
Vivian Hwa, $\mathrm{PhD}$

Cincinnati Center for Growth Disorders, Division of Endocrinology

Cincinnati Children's Hospital Medical Center

240 Albert Sabin Way, Cincinnati, OH 45229 (USA)

E-Mail vivian.hwa @ cchmc.org 
were performed on 3 unrelated children who share features of small for gestational age, short stature, and elevated serum IGF-I, but otherwise had clinical heterogeneity. Fluorescence-activated cell sorting (FACS) analysis of cell-surface IGF1R was performed on live primary cells derived from the patients. Results: Two novel IGF1R CNV and a heterozygous IGF1R nonsense variant were identified in the 3 patients. One CNV (4.492 Mb) was successfully called from WES, utilizing eXome-Hidden Markov Model (XHMM) analysis. FACS analysis of cell-surface IGF1R on live primary cells derived from the patients demonstrated a $\sim 50 \%$ reduction in IGF1R availability associated with the haploinsufficiency state. Conclusion: In addition to conventional methods, IGF1R CNV can be identified from WES data. FACS analysis of live primary cells is a promising method for efficiently evaluating and screening for IGF1R haploinsufficiency. Further investigations are necessary to delineate how comparable IGF1R availability leads to the wide spectrum of clinical phenotypes and variable responsiveness to rhGH therapy.

c 2017 S. Karger AG, Basel

\section{Introduction}

Normal human intrauterine and postnatal growth requires an intact insulin-like growth factor I (IGF-I) and IGF-I receptor (IGF1R) axis. IGF1R haploinsufficiency due to molecular defects is associated with impaired growth and indicates that a single allele of the IGF1R gene is insufficient for normal growth and development. A complete loss of IGF1R has yet to be reported in humans, and may be lethal, as was shown in rodent studies in which targeted ablation of the Igflr gene resulted in perinatal death $[1,2]$. Indeed, for the most hypomorphic of IGF1R mutations described to date (2 homozygous missense mutations $[3,4]$ and 2 compound heterozygous IGF1R mutations $[5,6])$, residual expression and function likely ensured survival, although clinical presentations were more severe than in patients who were IGF1R haploinsufficient [7, 8]. Current treatment options of recombinant human (rh) GH or rhIGF-I therapy, approved for multiple indications including idiopathic short stature and small for gestational age (SGA), remain a conundrum, as IGF1R-deficient patients exhibit IGF-I resistance, often with serum IGF-I concentrations well above the normal ranges.

Synthesized as a single polypeptide precursor, the IGF1R undergoes proteolytic cleavage into $\alpha$ - and $\beta$ chains and forms a tetramer $\left(\alpha_{2} \beta_{2}\right)$, with the extracellular $\alpha_{2}$-subunits involved in ligand binding and the intracel- lular $\beta_{2}$-subunits carrying the intrinsic tyrosine kinase functions necessary for signal transduction [9]. Ligand association leads to IGF1R autophosphorylation and activation of multiple downstream signaling pathways, including the phosphatidylinositol 3-kinase/AKT and MAPK/ERK pathways important for cell survival and growth [10]. In an IGF1R haploinsufficiency state, IGF-Iinduced IGF1R signaling is reduced [11-13], although binding of IGF-I may remain normal $[14,15]$, further stressing the necessity of biallelic expression of the IGF1R gene for full biological activity.

In this study, we report 3 new IGF1R haploinsufficiency cases and highlight (a) the unique application of whole exome sequencing (WES) data for assessing copy number variation $(\mathrm{CNV})$ in the genetic workup of short stature; (b) the utility of fluorescence-activated cell sorting (FACS) analysis as a promising method for efficiently evaluating cell-surface IGF1R availability using live primary cells derived from patients; and (c) the effectiveness of rhGH therapy for treating some patients. Our study expands the genetic and functional diagnosis for an IGF1R haploinsufficiency state, emphasizes the importance of including CNV analysis in the initial evaluation of children who present with clinical and biochemical features suggestive of IGF1R insufficiency, and raises questions of how comparable IGF1R availability results in variable clinical phenotypes and responsiveness to rhGH therapy.

\section{Materials and Methods}

\section{Clinical Reports}

Proband 1

Proband 1 (P1), an 8-year-old Chilean girl with short stature, was born at 35 weeks of gestation with a birth weight of $2.1 \mathrm{~kg}$, and a birth length of $42 \mathrm{~cm}$ (SDS -2.61), to nonconsanguineous parents. She showed catch-up growth (to the 25th percentile for height) until the age of 5 years when she started to deviate below this channel. At the age of 8.3 years, her height was $115.5 \mathrm{~cm}$ (SDS -2.06), her weight was $22.1 \mathrm{~kg}$ (SDS -0.92), her body mass index was 16.3 (SDS +0.25), and her head circumference was $51 \mathrm{~cm}$ (SDS $-1.0)$. The patient had proportional body segments and no dysmorphic features.

Her endocrine evaluations at the age of 8 years revealed elevated serum IGF-I (488 ng/mL, reference range [RR], 120-385) and serum IGFBP-3 (6.2 mg/L, RR, 2.2-6.5) for her prepubertal, chronological age. Her basal serum $\mathrm{GH}$ was $1.1 \mathrm{ng} / \mathrm{L}$, which peaked at $11.2 \mathrm{ng} / \mathrm{L}$ after stimulation with clonidine. A diagnosis of IGF-I insensitivity was made.

During this period, rhGH therapy starting at a relatively low dose of $0.117 \mathrm{mg} / \mathrm{kg} /$ week led to a clinically significant increase in her growth velocity. During rhGH treatment, her height shifted from below the $3 \mathrm{rd}$ percentile to approximately the 10th percentile at 12 years of age (Fig. 1a). As expected, her serum IGF-I concen- 

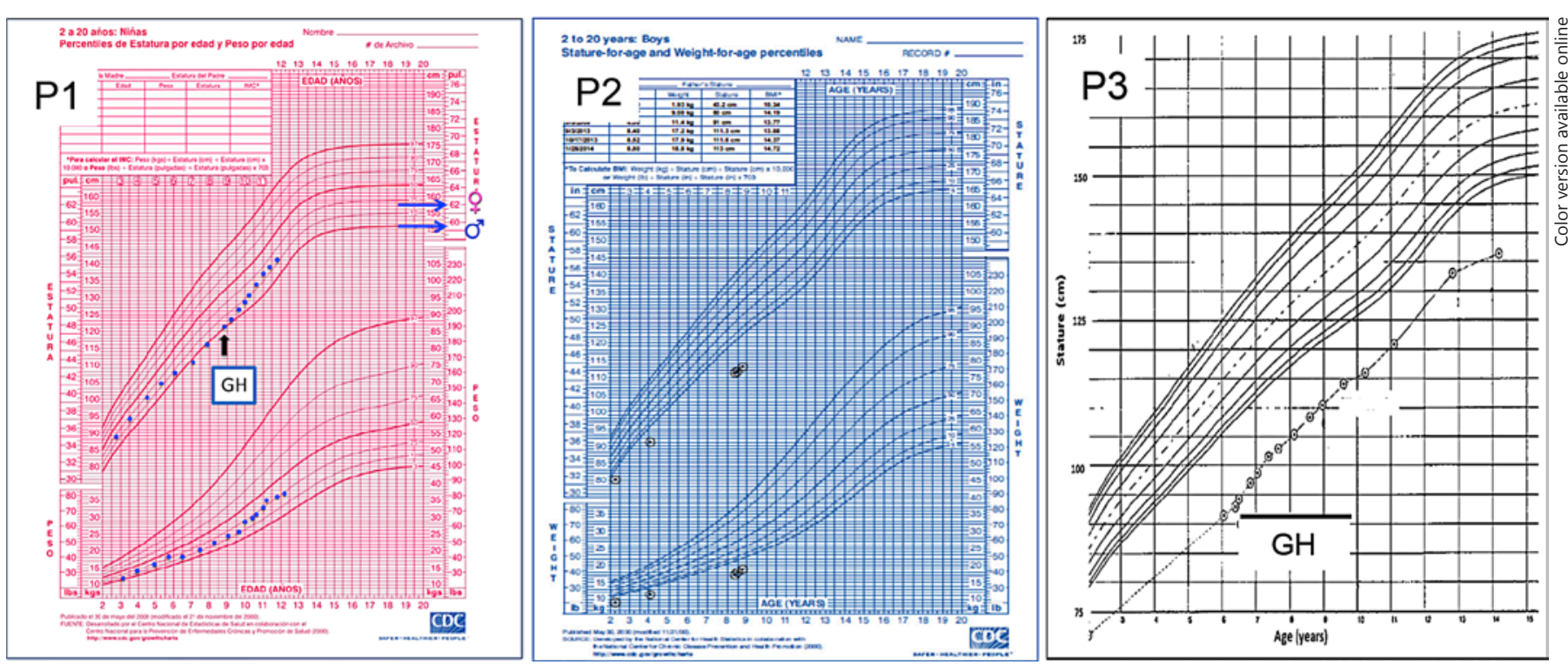

Fig. 1. Growth profiles of probands. a Growth chart of proband 1 (P1). The arrow indicates start of GH treatment. b Growth chart of proband 2 (P2). c Growth chart of proband 3 (P3) during GH treatment.

trations on rhGH therapy were high $(811-1,145 \mathrm{ng} / \mathrm{mL})$. Her pubertal development advanced normally, and she underwent menarche at 12.5 years of age.

Her family history revealed that her father is modestly short, with a height of $163 \mathrm{~cm}$ (SDS -1.93), whereas her mother's height is normal $(157 \mathrm{~cm}$, SDS -0.98) as is her 18-year-old brother's height $(168 \mathrm{~cm}, \mathrm{SDS}-1.2)$. A summary of the endocrine studies for $\mathrm{P} 1$ is shown in Table 1.

\section{Proband 2}

Proband 2 (P2) is an 8-year-old Caucasian boy with neurofibromatosis type 1 (NF-1) who presented with severe growth failure. He was born SGA at 36 weeks with a birth weight of $1.930 \mathrm{~kg}$ (SDS -2.25), a birth length of $43.2 \mathrm{~cm}$ (SDS -2.3), and a head circumference of $32.5 \mathrm{~cm}$ (SDS -1.5). His growth chart is shown in Figure $1 \mathrm{~b}$. He required therapy for mild motor and language delays in the toddler years. His brain magnetic resonance imaging showed a stable lesion (likely a glioma) in the left inferior cerebellar peduncle, with normal pituitary and optic nerve tracts.

The initial endocrine evaluations (Table 1) showed slow weight gain (SDS -2.5), growth failure (SDS -3.4), and mild microcephaly (head circumference SDS -2.0). Physical examination showed café-au-lait spots, a thin upper lip, fifth finger clinodactyly, and subcutaneous neurofibromas. His development was age appropriate; only symptoms of attention deficit and hyperactivity were observed.

His endocrine evaluation at the age of 8 years revealed serum IGF-I of $161 \mathrm{ng} / \mathrm{mL}$ and serum IGFBP-3 of $4.03 \mathrm{mg} / \mathrm{L}$, both normal for his chronological age. His $\mathrm{GH}$-binding protein was $916 \mathrm{pmol} / \mathrm{L}$; acid labile subunit was $8.8 \mathrm{mg} / \mathrm{L}$ and thyroxine was $2.1 \mathrm{ng} / \mathrm{dL}$, all within the normal range. His serum GH peaked at $15.5 \mathrm{ng} / \mathrm{mL}$ after stimulation with arginine/clonidine.
His family history revealed that his maternal grandmother is modestly short, with a height of $152 \mathrm{~cm}$ (SDS -1.8), whereas his paternal grandparents are normal statured. His mother, who also has NF-1, has a normal height of $160 \mathrm{~cm}$ (SDS -0.5) and his father's height is $178 \mathrm{~cm}$ (SDS 0.2). Clinical data for $\mathrm{P} 2$ are shown in Table 1.

\section{Proband 3}

Proband 3 (P3) is a 6-year-old Chinese girl with severe postnatal growth failure. She was born SGA from a term delivery with a birth weight of $1.65 \mathrm{~kg}$ (SDS -3.0); her birth length was not recorded. She underwent repair of a ventricular septal defect and an aortic coarctation in the neonatal period. She did not speak until the age of 3 years and was subsequently diagnosed with a central auditory processing disorder.

Her initial endocrine evaluation showed that her height was -5.2 SDS and her weight -5 SDS. The physical examination showed mild mid-face hypoplasia, crowded dentition, and ocular hypertelorism. Her serum IGF-I was $296 \mathrm{ng} / \mathrm{mL}$ (RR, 52-297) and IGFBP-3 was normal. GH stimulation test with clonidine peaked at $35 \mathrm{ng} / \mathrm{mL}$.

During this period, rhGH therapy was started at a dose of 0.30 $\mathrm{mg} / \mathrm{kg} /$ week (Fig. 1c). From the age of 6.3 to 9.5 years, her height improved to -4.1 SDS with persistently elevated IGF-I and IGFBP-3 concentrations. rhGH was discontinued at the age of 10 years after growth failed to improve on a higher rhGH dose of $0.42 \mathrm{mg} / \mathrm{kg} /$ week, despite an elevated serum IGF-I concentration of $709 \mathrm{ng} / \mathrm{mL}$ (RR, 65-457) and an IGFBP-3 of $6.5 \mathrm{mg} / \mathrm{L}(\mathrm{RR}, 2.9-5.2)$. At the age of 12.8 years, she had Tanner 2 breast and Tanner 3 pubic hair, irregular menses, a bone age of 13 years, and an improved growth rate of $7.1 \mathrm{~cm} /$ year off rhGH, with a markedly high serum IGF-I concentration of $1,183 \mathrm{ng} / \mathrm{mL}$. At the age of 14.2 years, her height 
Table 1. Summary of biochemical data of affected probands

\begin{tabular}{|c|c|c|c|}
\hline & $\mathrm{P} 1$ & P2 & P3 \\
\hline Gender & female & male & female \\
\hline Gestational age, weeks & 35 & 36 & term delivery \\
\hline Birth length (SDS), cm & $42(-2.61)$ & $43.2(-2.3)$ & not recorded \\
\hline Birth weight (SDS), kg & $2.1(-1.57)$ & $1.93(-2.25)$ & $1.65(-3.0)$ \\
\hline Head circumference (SDS), cm & NA & $32.5(-1.5)$ & NA \\
\hline \multicolumn{4}{|l|}{ First consultation } \\
\hline Age, years & 8.3 & 8 & 6 \\
\hline Bone age & 7 years & 7 years & 5 years 9 months \\
\hline Height (SDS), cm & $115.5(-2.06)$ & $(-3.4)$ & $(-5.2)$ \\
\hline Weight (SDS), $\mathrm{kg}$ & $22.1(-0.92)$ & $(-2.5)$ & $(-5.0)$ \\
\hline Head circumference (SDS), cm & $51(-1.0)$ & $(-2.0)$ & - \\
\hline Glucose, $\mathrm{mg} / \mathrm{dL}$ & 85 & - & - \\
\hline $\mathrm{TSH}, \mu \mathrm{IU} / \mathrm{mL}$ & 4.35 & - & 0.88 \\
\hline $\mathrm{T} 4$ free, $\mathrm{ng} / \mathrm{dL}$ & 1.22 & 2.1 & 1.7 \\
\hline Stimulated GH (clonidine), $\mathrm{ng} / \mathrm{mL}$ & 11.2 & 15.5 & 35 \\
\hline IGF-I (RR), ng/mL & $488(120-385)$ & $161(52-231)$ & $296(52-297)$ \\
\hline IGFBP-3 (RR), mg/L & $6.2(2.2-6.5)$ & $4.03(2.1-4.2)$ & $4.5(1.3-5.6)$ \\
\hline ALS (RR), mg/L & - & $8.8(4.2-13)$ & - \\
\hline GHBP (RR), pmol/L & - & $916(267-1,638)$ & - \\
\hline Brain MRI & normal & $\begin{array}{l}\text { stable lesion in left inferior } \\
\text { cerebellar peduncle }\end{array}$ & - \\
\hline Post-rhGH treatment & & NA & \\
\hline Age, years & 12.08 & & 10 \\
\hline Height, $\mathrm{cm}$ & -1.4 & & -4.1 \\
\hline IGF-1 (RR), ng/mL & $1,145(143-693)$ & & $709(65-457)$ \\
\hline IGFBP-3 (RR), mg/L & $8(2.4-8.4)$ & & $6.5(2.9-5.2)$ \\
\hline
\end{tabular}

NA, not available; ALS, acid labile subunit; GHBP, GH-binding protein; MRI, magnetic resonance imaging; $\mathrm{RR}$, reference range.

was $136.4 \mathrm{~cm}(-3.7$ SDS). Clinical data for P3 are summarized in Table 1.

Her family history revealed that her father's height is normal at $170 \mathrm{~cm}$ (SDS -0.2) and her mother's height is also normal $(163 \mathrm{~cm}$, SDS -0.2). She has 1 sister, also reported with normal linear growth.

\section{Samples from Probands and Family Members}

Blood samples from the probands and all immediate family members were collected for genetic studies with informed consent and in compliance with the respective institutional review boards. Serum assays for P1 were performed by standard techniques in the IDIMI laboratory. Serum IGFBP-3 was measured by an immunoradiometric assay from Diagnostic System Laboratories (Webster, TX, USA). Serum assays for P2 and P3 were measured as previously described [11].

\section{Primary Dermal Fibroblast Cell Cultures}

Primary fibroblast cultures were established from skin biopsies taken from the forearm of the index patients $(\mathrm{P} 1, \mathrm{P} 2)$ and from a control subject with normal pre- and postnatal growth. Samples were collected in compliance with the study protocol approved by the institutional review boards of San Borja-Arriarán Clinical Hospital, Cincinnati Children's Hospital Medical Center, and Oregon
Health \& Science University. Fibroblast cultures were maintained as previously described [11]

\section{Genomic DNA and cDNA}

Extraction of genomic DNA from whole blood or primary fibroblast cultures, total RNA from primary fibroblast cultures, synthesis of cDNA, and Sanger sequencing of the IGF1R gene have been previously described [11]. The primers for PCR amplification of exon 13 are as follows: forward, 5'-GCCAAGGGTGTGGTGAAAGATGAA- $3^{\prime}$; reverse, $5^{\prime}$-ACCACATGGTGACAATTGAACTCCTTCATC- $3^{\prime}$.

\section{Fluorescence in situ Hybridization Analysis}

The RP11-602 fluorescence in situ hybridization (FISH) probe and standard cytogenetic techniques were used to confirm the deletion observed in P2.

\section{Chromosomal Microarray}

Single nucleotide polymorphism (SNP) microarray analysis was performed on genomic DNA samples from P2. The Illumina Infinium assay was performed on DNA samples using the CytoSNP-850K BeadChip platform. B-allele frequency and Log2R ratio were analyzed with the Illumina GenomeStudio analysis software, and DNA copy number changes were prioritized using cnvParti- 
tion software at Cincinnati Children's Hospital Medical Center Human Genetics Diagnostic Laboratories.

\section{Whole Exome Sequencing}

WES was performed on DNA extracted from whole blood from P3 and her parents. After library construction, hybridization and capture were performed using the Illumina's Rapid Capture Exome Kit and following the manufacturer's suggested protocol. Sequencing, downstream sequence alignment, variant calling, and variant annotation were performed as previously described [16]. Exomes were sequenced with mean target coverage $>80 \mathrm{X}$. Variants were then filtered for rare (minor allele frequency $<1 \%$ ) nonsynonymous variants that segregated with the phenotype as previously described [16]. CNV was called using the eXome-Hidden Markov Model (XHMM) algorithm [17] using default parameters and adjustment for the first 5 principal components. CNV were jointly called and genotyped along with 189 additional samples sequenced on the same platform, including samples from the parents of P3.

\section{Flow Cytometry Analysis by FACS}

Flow cytometric analysis by FACS of cell-surface IGF1R on live primary fibroblasts was performed (for detailed procedure, see online suppl. Methods; see www.karger.com/doi/10.1159/000464143 for all online suppl. material). Briefly, adherent fibroblasts were gently lifted with $0.05 \%$ trypsin/5 mM EDTA after IGF-I treatment (100 ng/mL, $24 \mathrm{~h}$ ), trypsin activity were neutralized with fetal bovine serum supplemented media, and RPMI-washed suspended cells in aliquots of $100 \mu \mathrm{L}\left(10^{6}\right.$ cells/mL RPMI) were processed for FACS analysis as for PBMCs (see below). All experiments were performed in triplicates, at least 2 independent times.

PBMCs were prepared for FACS of cell-surface IGF1R [18]. Briefly, cells, treated for $1 \mathrm{~h}$ with or without $50 \mathrm{ng} / \mathrm{mL}$ IGF-I (GroPep Ltd, Thebarton, SA, Australia), were incubated with phycoerythrin (PE)-conjugated anti-human IGF1R- $\alpha$ (CD221; BD Biosciences, San Jose, CA, USA) for $30 \mathrm{~min}\left(4^{\circ} \mathrm{C}\right.$ in the dark), and stained with $0.25 \%$ propidium iodide (PI). For each sample, a total of 100,000 live PBMCs or 20,000 live fibroblasts (PI-negative cells) were acquired via a FACSCalibur flow cytometer (BD Biosciences), and the fluorescence emitted by IGF1R-PE-labeled cells (gated as shown in online suppl. Fig. 1) was analyzed using FCS Express 3 analysis software (De Novo Software, Los Angeles, CA, USA).

\section{Western Immunoblot Analysis}

Cultured fibroblasts were serum starved overnight prior to IGF-I treatment (15 or $20 \mathrm{~min}$ ), cell lysates collected and subject to Western immunoblot analyses [19]. Rabbit polyclonal IgG against phospho-AKT (dilution 1:1,000) and rabbit monoclonal IgG against Akt (dilution 1:2,000) were purchased from Cell Signaling Technologies (Beverly, MA, USA). The anti-rabbit IgG secondary antibody was purchased from Amersham-Pharmacia Biotech (Uppsala, Sweden).

\section{Results}

Identification of Novel Heterozygous IGF1R Variants

Clinical and biochemical profiles of the 3 probands were consistent with resistance to the growth-promot- ing effects of IGF-I. Defective IGF1R expression was considered. Targeted sequencing of the IGF1R gene of genomic DNA (whole blood or cultured fibroblasts) from P1 identified a heterozygous IGF1R $c .2629 C>T$ variant (rs150221450; minor allele frequency of 8.237e-06, Exome Aggregation Consortium Browser) in exon 13 (Fig. 2a), a transition variant confirmed in Sanger sequencing of the $I G F 1 R$ cDNA. Analysis of the genomic DNA from the other family members revealed that the father was also heterozygous for $c .2629 C>T$. The $c 2629 C>T$ changed codon Arg877 (CGA) to a stop codon (TGA), p.R877*, generating a predicted truncated IGF1R protein which, if expressed, would be unable to anchor to the cell membrane.

In contrast to P1, P2 and P3 were found to carry $\mathrm{CNV}$ of IGF1R. For P2, SNP microarray analysis identified an unique heterozygous interstitial deletion of approximately $0.282 \mathrm{Mb}$ on chromosome 15 [46 XY del(15)q26.3(99,438,083-99,720,341)]. This region includes exons 4-21 of the IGF1R gene (Fig. $2 \mathrm{~b}$ ), the deletion of which resulted in loss of $\sim 75 \%$ of the IGF1R-coding sequences, in addition to 3 other genes that have unknown phenotypic effects (PGPEP1L, SYNM, and TTC23). Parental study of chromosome 15q26.3 by FISH analysis confirmed a maternally inherited deletion (Fig. 2b).

The IGF1R CNV in P3 was identified through re-evaluating WES data for $\mathrm{CNV}$, an analysis procedure not routinely performed with WES. Initial analysis of WES (P3 and parents) utilizing stringent filtering of called rare variants did not reveal an obvious genetic cause for the phenotypic presentation. Analysis was subsequently expanded to $\mathrm{CNV}$ discovery, applying the XHMM algorithm [17]. A total of $27 \mathrm{CNV}$ (16 deletions and 11 duplications) were successfully detected in the patient's sample, including a large $4.492-\mathrm{Mb}$ heterozygous deletion on chromosome 15 [46 XX del(15)(q26.2:qter)(97,970,832102,463,314)] (Fig. 2c). The CNV was not present in either the parents, or in the 189 additional exomes that were simultaneously analyzed, suggesting that the $4.492-\mathrm{Mb}$ deletion was de novo in P3. All other CNV were either inherited from the parents and/or were present in additional individuals in the $\mathrm{CNV}$ call set.

The 4.492-Mb CNV partially or fully overlapped a total of 28 genes, including the IGF1R gene (MIM 270450). Five of the other genes within the deletion are associated with Mendelian phenotypes that are autosomal recessive (MIM 613195, 615023, 614340, 615113, 605282), and we did not find additional rare protein-altering variants within their sequences. While it is possible that any individual gene, or a combination of these 5 genes in the $4.492-\mathrm{Mb}$ deletion, could have contributed to the com- 
Fig. 2. Molecular defects identified in probands. Probands are indicated by arrows. Height SDS is indicated. Family members not genetically analyzed are indicated with a question mark. a Electropherogram of the heterozygous IGF1R c.2629C $>T$ variant in P1, compared to normal sequences, and segregation of the variant (half shaded) in the family. b For P2: heterozygous 15q23.3 deletion involving the $0.282-\mathrm{Mb}$ region which included exon 4-21 of the IGF1R gene. Co-segregation of the heterozygous $15 \mathrm{q} 23.3$ deletion and NF1 phenotype in the family (half-shaded). c De novo heterozygous 4.492-Mb deletion on chromosome 15 [46 XX del(15)(q26.2:qter) $(97,970,832-$ $102,463,314)]$ identified in P3.
P1

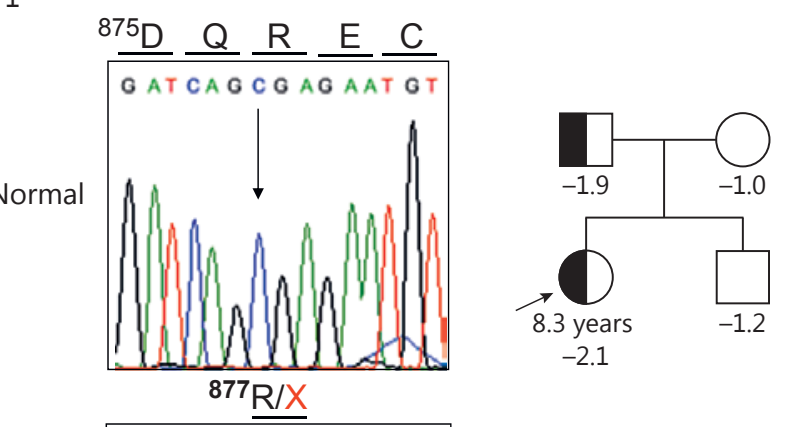

P1

a

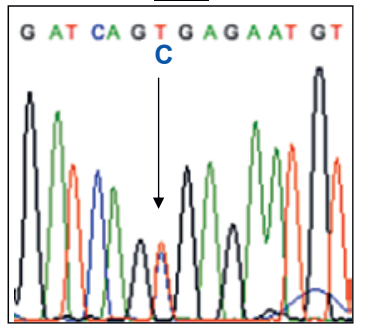

P2

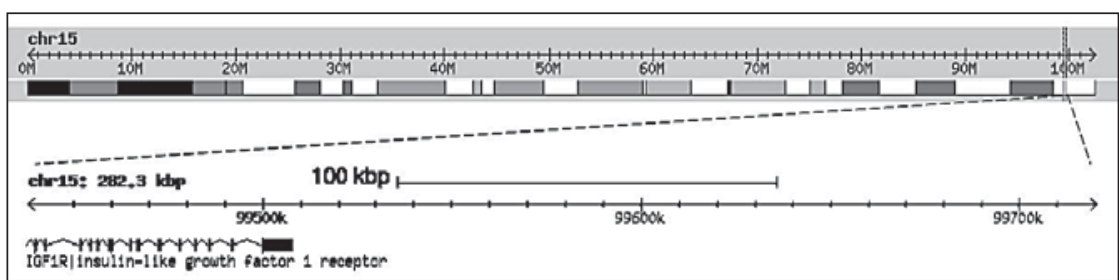

b

P3

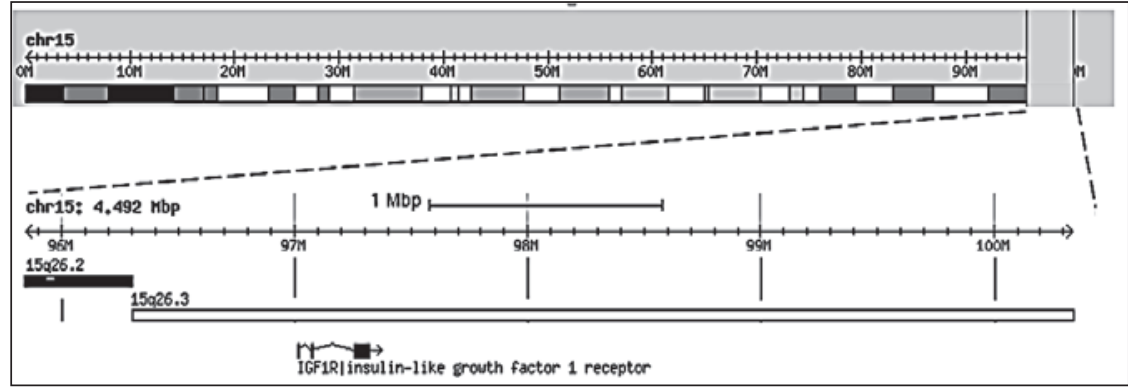

C
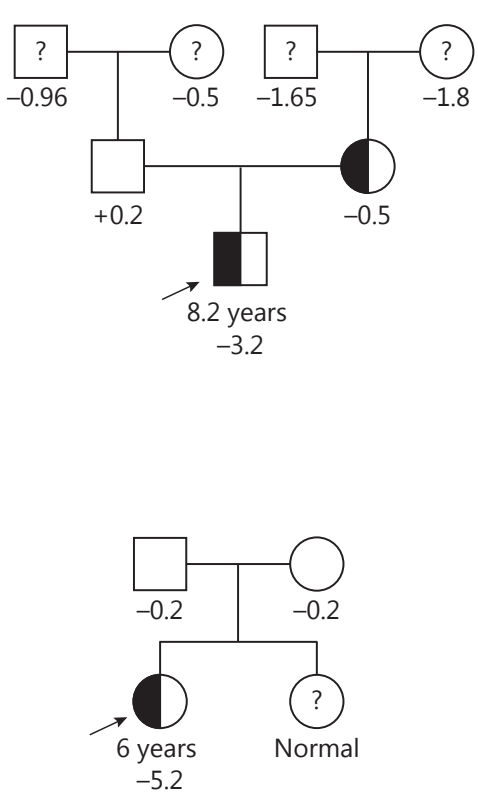

plex phenotype, a database search of each gene for functions and association with diseases (OMIM, PubMed, and UniProt) supports deletion of IGF1R as the primary contributor. Of note, no other rare protein-altering sequence variants in IGF1R were identified. P3 was treated with
rhGH and demonstrated only a modest growth response to GH therapy (Fig. 1c), despite markedly increased serum IGF-I and IGFBP-3 concentrations. Samples for further analysis of IGF1R protein expression and functions were, unfortunately, not available. 
FACS of Cell-Surface IGF1R on Live Primary Cells

An IGF1R haploinsufficiency state was indicated for each of our 3 probands. We had previously demonstrated that IGF1R haploinsufficiency due to nonsense-mediated mRNA decay, IGF1R c.3348_3366dup [11], and a hypomorphic IGF1R p.E121K/E234K compound heterozygous mutation [6], resulted in significantly reduced total IGF1R protein expressions with concomitant reduction in IGF-I-induced signaling. To assess if IGF1R expression was similarly altered in our present patients, we employed flow cytometry analysis by FACS of live cells derived from P1 and P2, probing for the presence of cell-surface IGFIR (Fig. 3). Unlike methods for assessing total IGF1R expression, FACS analysis provides relative quantitation of expressed IGF1R that had translocated appropriately to the cell surface, thus reflecting in vivo availability of IGF1R.

The geometric mean fluorescence intensities (MFI) emitted by anti-IGF1R-PE-probed live dermal fibroblasts from P1 and P2 were compared to the MFI from our panel of normal (C1) and previously characterized IGF1Rdeficient fibroblasts. Fibroblasts carrying the previously described IGF1R c.3348_3366dup or IGF1R p.E121K/ E234K mutations had basal MFI that were significantly reduced ( $46 \pm 9 \% \mathrm{SD}$ and $37 \pm 4 \% \mathrm{SD}$, respectively) relative to untreated C1 (arbitrarily assigned a MFI of $100 \%$; Fig. 3a). The MFI of fibroblasts carrying the heterozygous IGF1R p.R877* variant (P1) or IGF1R CNV (P2) were similarly reduced at $39 \pm 9 \% \mathrm{SD}$ and $46 \pm 13 \% \mathrm{SD}$, respectively (Fig. 3a), and comparable to our proven IGF1R haploinsufficient and hypomorphic cells. When $\mathrm{C} 1$ and IGF1R haploinsufficient fibroblasts (c.3348_3366dup, p.R877*, or IGF1R CNV) were treated with IGF-I (100 $\mathrm{ng} / \mathrm{mL}, 24 \mathrm{~h}$ ), the emitted MFI were found to be reproducibly, and comparably, further reduced (Fig. 3a, b). In contrast, compound heterozygous IGF1R p.E121K/ E234K fibroblasts demonstrated poor responsiveness to IGF-I (Fig. 3a). Altogether, the results suggest that availability of cell-surface wild-type IGF1R significantly decreases after exposure to IGF-I, possibly due to ligandreceptor internalization, and this phenomenon was observed for normal as well as IGF1R haploinsufficient cells.

We had previously shown that a deficiency in IGF1R could be detected by FACS analysis of PBMCs [18], a biological sample much more readily accessible than primary dermal fibroblasts established from skin biopsies. Since we had access to whole blood samples from P2 and his parents, FACS analysis of isolated live PBMCs for cellsurface IGF1R was performed to determine whether there might be variations in IGF1R expression, depending on cell type. Of note, the mother of P2 carries the same
IGF1R CNV while the father was wild-type for the CNV. As shown in Figure $3 c$ and d, the fluorescence intensity emitted by anti-IGF1R-PE-labeled PBMCs from P2 (52 \pm $6 \% \mathrm{SD})$ and the mother ( $50 \pm 7 \% \mathrm{SD})$ were similarly and markedly reduced when compared to both normal PBMCs and PBMCs from the father ( $87 \pm 18 \%$ SD). For all PBMC samples analyzed, exposure to $50 \mathrm{ng} / \mathrm{mL}$ IGF-I for $1 \mathrm{~h}$ was sufficient to further reduce detectable cellsurface IGF1R (Fig. 3d).

\section{IGF-I-Induced IGF1R Signaling}

To confirm that IGF1R haploinsufficiency in P1 and P2 correlated with reduced IGF1R signaling, primary dermal fibroblast cultures were stimulated with $100 \mathrm{ng} /$ $\mathrm{mL}$ of IGF-I for $20 \mathrm{~min}$ and phosphorylation of Thr308 on AKT, phospho- $T^{308}$-AKT, assessed. Primary fibroblasts from both patients demonstrated decreased $\mathrm{T}^{308}$ AKT phosphorylation compared to $\mathrm{C} 1$ cells (Fig. 3e).

\section{Discussion}

The importance of having 2 intact alleles of the IGF1R gene for normal intrauterine and postnatal growth is supported by the recognition of IGF1R haploinsufficiency as causal of pre- and postnatal growth retardation [8]. $I G F 1 R$ haploinsufficiency can be the consequence of allelic loss of $I G F 1 R$ due to chromosomal 15q26 deletions (first reported in 1991 [20]; P2 and P3 in this report) or due to specific allelic IGF1R mutations that abrogate mRNA [11] or protein expression (P1 in this report). Here, we demonstrated that cell-surface IGF1R levels were reduced by at least $50 \%$ when live primary cells, confirmed genetically for IGF1R haploinsufficiency, were analyzed by FACS, and this reduction correlated to reduced IGF-I-induced IGF1R signaling. This implies that biallelic protein expression is critical for maintaining normal cell-surface IGF1R availability and function. These results also serve to highlight FACS analysis of primary cells derived from patients as an efficient method for evaluating IGF1R haploinsufficiency. Future studies will include verifying the uniformity of cell-surface IGF1R expression in the different subpopulations of normal PBMCs and whether expression might be influenced by age or gender.

Cell-surface IGF1R availability was indistinguishable amongst our IGF1R haploinsufficient patients, who shared features of SGA and poor postnatal growth despite normal to markedly elevated serum IGF-I concentrations. Other clinical and biochemical features, however, including responsiveness to $\mathrm{rhGH}$ therapy $[8,21]$, were 


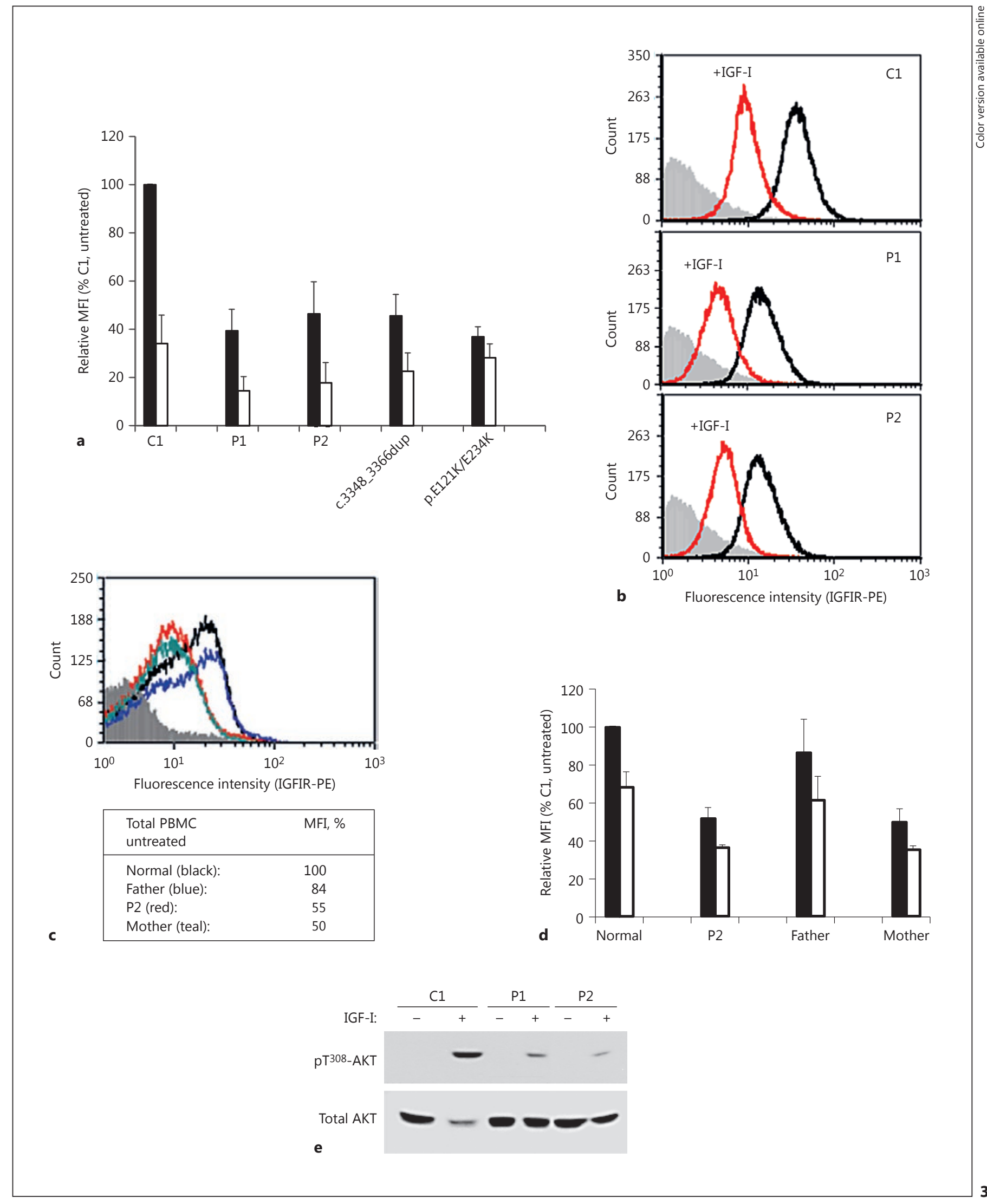

(For legend see next page.) 
highly variable as has been previously reported $[8,22]$. Both P1, carrying the heterozygous nonsense variant IGF1R p.R877*, and her father who carried the same variant, exhibited mild short stature (height SDS of -2.06 and -1.93 , respectively) but had no other apparent phenotypic anomalies. The p.R877* nonsense mutation abrogated C879-mediated disulfide formation necessary for a functional IGF1R $\alpha-\beta$ monomer, which, together with a lack of detectable truncated p.R877* peptides (either cell-associated or secreted, data not shown), support their IGF1R haploinsufficiency state. Of note, the p.R877* variant (c.2629C $>$ T, rs150221450), although not novel, is extremely rare as it was found in only 1 in 121,408 IGF1R alleles sequenced (NCBI dbSNP and ExAC databases) with clinical significance unknown. Our results provide strong evidence that this variant is likely to be the underlying cause of the mild short stature observed in this family.

In contrast to P1, P2 and P3 exhibited pronounced short stature and other phenotypic anomalies. Both probands carry IGF1R CNV, although P3, who carried a significantly larger chromosomal 15q26 deletion (4.5 Mb), was the more severely affected of the two, with a phenotype consistent with chromosome 15q26-qter deletion syndrome (MIM 612626) including cardiac defects, facial dysmorphism, auditory processing disorder, crowded dentition, and ocular hypertelorism. P2, in addition to carrying a maternally inherited IGF1R CNV, was also diagnosed with NF-1, but his growth abnormalities were not typical of those more commonly associated with NF-1 (macrocrania, reduced pubertal growth spurt in boys, and, in some, overweight status) [23]. Interestingly, it remains unclear why the mother of P2, who was IGF1R haploinsufficient by both genetic and functional assessments, was of normal stature. Altogether, the diverse spectrum of presentations by P2 and P3 may be conse-

Fig. 3. IGF1R expression and functional analysis. FACS analysis of cell-surface IGF1R, labeled by PE-conjugated anti-human IGF1Ralpha antibody, on live primary cells derived from affected patients. a The geometric mean fluorescence intensity (MFI, $y$ axis) emitted by labeled primary fibroblasts, untreated (black bars) and IGF-I treated (100 $\mathrm{ng} / \mathrm{mL}, 24 \mathrm{~h}$; white bars), is presented relative to MFI of normal, untreated, $\mathrm{C} 1$ fibroblasts, which was arbitrarily assigned a value of $100 \%$. Experiments were performed at least 3 independent times, each time in duplicates. P1: R877X; P2: 15q26.3 deletion $(0.282 \mathrm{Mb})$. b Representative collated emitted fluorescence (log scale fluorescence Intensity, $x$ axis) of live fibroblasts (counts, $y$ axis), untreated (black graphs) and IGF-I treated (red graphs) for $\mathrm{C} 1, \mathrm{P} 1$, and $\mathrm{P} 2$. The gray-shaded region indicates back- quences of $\mathrm{CNV}$ involving contiguous genes/chromosomal regions in addition to the IGF1R gene [22, 24-26].

The inability of targeted Sanger sequencing or WES variant analysis to detect gross allelic deletions of IGF1R illustrates the importance of including CNV analysis in the initial evaluation of children who present with preand postnatal growth failure in the presence of normal to elevated serum IGF-I concentrations suggestive of IGF1R insufficiency. Chromosomal IGF1R deletions can be readily identified by conventional methods, including karyotype (for large deletions), chromosomal microarrays, and SNP genotyping arrays, as was performed for $\mathrm{P} 2$, although it is of note that the $0.282-\mathrm{Mb}$ deletion was on the border of resolution for microarray analysis. Multiplex ligation probe amplification applications have also detected IGF1R CNV in affected patients [13, 27]. The limited resolution of all these methods, however, requires additional methodologies to delineate boundaries of CNV. For P3, we leveraged existing WES data to serve as a basis for CNV discovery, an application that provides much finer resolution (less than $1 \mathrm{~kb}$ ) than conventional $\mathrm{CNV}$ methods. WES data generated from P3 and her parents had not identified candidate single nucleotide variations of significance, but through XHMM analysis [17], which is a relatively sensitive and specific algorithm for detecting rare, large CNV [28-30], $27 \mathrm{CNV}$ in P3 were uncovered. Of these, only 1 , a $4.492-\mathrm{Mb}$ heterozygous chromosome 15 deletion that spans 28 genes, including the entire IGF1R gene, was unique to P3. Our finding of an IGF1R deletion in $\mathrm{P} 3$, therefore, supports the efficacy and efficiency of using exome sequencing for both variant and $\mathrm{CNV}$ detection, and is in line with the proposed "exome-first" paradigm for clinical investigations of genetic defects [28]. While successfully applied to our present case, additional algorithm refinement and testing will likely be necessary before these approaches can be widely

ground fluorescence emitted by unlabeled and untreated fibroblast control. c Detection of cell-surface IGF1R on live PBMCs from P2 (red) and parents (mother, teal; father, blue) compared with normal PBMCs (black). The gray-shaded region indicates background fluorescence of unlabeled and untreated PBMC control. The geometric MFI detected in normal PBMCs was given an arbitrary unit of $100 \%$. d The MFI ( $Y$ axis) of labeled PBMC in c upon IGF-I treatment $(50 \mathrm{ng} / \mathrm{mL}, 1 \mathrm{~h})$ compared to untreated (black bars), performed 2 independent times, each time in duplicates. Normal PBMCs, untreated, were given an arbitrary unit of $100 \%$. e Representative Western immunoblot of primary fibroblasts treated with IGF-I (100 ng/mL, $20 \mathrm{~min}$ ). Colors refer to the online version only. 
applied clinically in the genetic workup for patients with rare diseases.

Finally, therapeutic options for patients with IGF1R haploinsufficiency are currently limited to $\mathrm{rhGH}$, as the majority of these patients are born SGA without catch-up growth, a clinical condition approved for rhGH therapy. While long-term treatment, starting at a young age, has been successful for improving stature for some patients $[5,13,21]$, including for P1 who had mild short stature, overall responsiveness has been highly variable $[8,21]$. P3, for example, improved height by only 1 SD with 3 years of rhGH therapy, reaching a height SDS of -4.1 at age 9.5 years, and no catch-up growth was reported for the patient with IGF1R haploinsufficiency due to the c.3348_3366dup19 mutation [11]. P2 was not treated with rhGH because of concerns about potential impact on his NF-1 condition. The reason(s) for variable responsiveness to rhGH remains to be fully elucidated, with treatment tempered by concerns of extreme elevations of serum IGF-I concentrations, as was observed for P1 and P3. Continued monitoring of serum IGF-I and adjustment of dosage is highly recommended.

In summary, the molecular basis of IGF1R haploinsufficiency can be established by multiple methods, including utilizing genome-wide data for uncovering IGF1R $\mathrm{CNV}$, as demonstrated in this report. Our application highlights how genome-wide data can serve the dual purpose of variant and CNV discovery. FACS analyses of live primary cells derived from IGF1R haploinsufficient patients supported the genetic findings and, moreover, provide valuable insights into cell-surface receptor availability critical for growth-promoting responses. Further investigations are necessary to delineate mechanisms of how seemingly comparable IGF1R availability can result in a wide spectrum of clinical phenotypes and variable responsiveness to rhGH therapy.

\section{Disclosure Statement}

P.F.B. is on the Consultant/Advisory Boards for Novo Nordisk, Sandoz (Novartis), and Versartis. H.S. is on the Medical Advisory Board and Speakers Bureau for Alexion Pharmaceuticals, Inc. P.O., M.C.G., S.F.A., M.H.G., P.K., R.G.R., A.D., F.C., and V.H. have nothing to disclose.

\section{Funding Sources}

This study was supported by funding from NIH NICHHD 1K23HD073351 to A.D.; NIH NICHHD R01HD078592 to V.H.; fellowship from the Latin American Society for Pediatric Endocrinology (SLEP) to P.O.; and grant support from Versatis to P.F.B.

\section{References}

1 Baker J, Liu JP, Robertson EJ, Efstratiadis A: Role of insulin-like growth factors in embryonic and postnatal growth. Cell 1993;75:7382.

-2 Liu JP, Baker J, Perkins AS, Robertson EJ, Efstratiadis A: Mice carrying null mutations of the genes encoding insulin-like growth factor I (Igf-I) and type I IGF receptor (Igflr). Cell 1993;75:59-72.

-3 Gannagé-Yared M-H, Klammt J, Chouery E, Corbani S, Mégarbané H, Ghoch JA, Choucair N, Pfaffle R, Mégarbané A: Homozygous mutation of the IGF1 receptor gene in a patient with severe pre- and postnatal growth failure and congenital malformations. Eur J Endocrinol 2013;168:K1-K7.

-4 Prontera P, Micale L, Verrotti A, Napolioni V, Stangoni G, Merla G: A new homozygous IGF1R variant defines a clinically recognizable incomplete dominant form of SHORT syndrome. Hum Mutat 2015;36:1043-1047.
5 Abuzzahab MJ, Schneider A, Goddard A, Grigorescu F, Lautier C, Keller E, Kiess W, Klammt J, Kratzsch J, Osgood D, Pfaffle R, Raile K, Seidel B, Smith RJ, Chernausek SD: IGF-I receptor mutations resulting in intrauterine and postnatal growth retardation. N Engl J Med 2003;349:2211-2222.

6 Fang P, Cho YH, Derr MA, Rosenfeld RG, Hwa V, Cowell CT: Severe short stature caused by novel compound heterozygous mutations of the insulin-like growth factor 1 receptor (IGF1R). J Clin Endocrinol Metab 2012;97:E243-E247.

7 David A, Hwa V, Metherell LA, Netchine I, Camacho-Hubner C, Clark AJ, Rosenfeld RG, Savage MO: Evidence for a continuum of genetic, phenotypic, and biochemical abnormalities in children with growth hormone insensitivity. Endo Rev 2011;32:472-497.

-8 Klammt J, Kiess W, Pfaffle R: IGFIR mutations as cause of SGA. Best Pract Res Clin Endocrinol Metab 2011;25:191-206.

-9 Adams TE, Epa VC, Garrett TP, Ward CW: Structure and function of the type 1 insulinlike growth factor receptor. Cell Mol Life Sci 2000;57:1050-1093.
10 Leroith D, Werner H, Beitner-Johnson D, Roberts CT Jr: Molecular and cellular aspects of the insulin-like growth factor 1 receptor. Endocr Rev 1995;16:143-163.

11 Fang P, Schwartz ID, Johnson BD, Derr MA, Roberts JCT, Hwa V, Rosenfeld RG: Familal short stature caused by haploinsufficiency of the insulin-like growth factor I receptor due to nonsense-mediated messenger ribonucleic acid decay. J Clin Endocrinol Metab 2009;94: 1740-1747.

12 Choi J-H, Kang M, Kim G-H, Hong M, Jin HY, Lee B-H, Park J-Y, Lee S-M, Seo E-J, Yoo $\mathrm{H}-\mathrm{W}$ : Clinical and functional characteristics of a novel heterozygous mutation of the IGF1R gene and IGF1R haploinsufficiency due to terminal 15q26.2-> qter deletion in patients with intrauterine growth retardation and postnatal catch-up growth failure. J Clin Endocrinol Metab 2011;96:E130-E134. 
13 Walenkamp MJ, de Muinck Keizer-Schrama SM, de Mos M, Kalf ME, van Duyvenvoorde HA, Boot AM, Kant SG, White SJ, Losekoot M, Den Dunnen JT, Karperien M, Wit JM: Successful long-term growth hormone therapy in a girl with haploinsufficiency of the insulin-like growth factor-I receptor due to a terminal $15 \mathrm{q} 26.2->$ qter deletion detected by multiplex ligation probe amplification. J Clin Endocrinol Metab 2008;93:2421-2425.

14 Siebler T, Lopaczynski W, Terry CL, Casella SJ, Munson P, De Leon DD, Phang L, Blakemore KJ, McEvoy RC, Kelley RI, et al: Insulinlike growth factor I receptor expression and function in fibroblasts from two patients with deletion of the distal long arm of chromosome 15. J Clin Endocrinol Metab 1995;80:34473457.

15 Hammer E, Kutsche K, Haag F, Ullrich K, Sudbrak R, Willig RP, Braulke T, Kubler B: Mono-allelic expression of the IGF-I receptor does not affect IGF responses in human fibroblasts. Eur J Endocrinol 2004;151:521-529.

16 Guo MH, Shen Y, Walvoord EC, Miller TC, Moon JE, Hirschhorn JN, Dauber A: Whole exome sequencing to identify genetic causes of short stature. Horm Res Paediatr 2014;82: 44-52.

17 Fromer M, Moran JL, Chambert K, Banks E, Bergen SE, Ruderfer DM, Handsaker RE, McCarroll SA, O’Donovan MC, Owen MJ, Kirov G, Sullivan PF, Hultman CM, Sklar P, Purcell SM: Discovery and statistical genotyping of copy-number variation from whole-exome sequencing depth. Am J Hum Genet 2012;91: 597-607.

18 Wang SR, Carmichael H, Andrew SF, Miller TC, Moon JE, Derr MA, Hwa V, Hirschhorn JN, Dauber A: Large scale pooled next-generation sequencing of 1077 genes to identify causes of short stature. J Clin Endocrinol Metab 2013;98:E1428-E1437.
9 Fang P, Riedl S, Amselem S, Pratt KL, Little BM, Haeusler G, Hwa V, Frisch H, Rosenfeld RG: Primary growth hormone $(\mathrm{GH})$ insensitivity insulin-like growth factor deficiency caused by novel compound heterozygous mutations of the $\mathrm{GH}$ receptor gene: genetic and functional studies of simple and compound heterozygous state. J Clin Endocrinol Metab 2007;92:2223-2231.

20 Roback EW, Barakat AJ, Dev VG, Mbikay M, Chretien M, Butler MG: An infant with deletion of the distal long arm of chromosome 15 (q26.1--qter) and loss of insulin-like growth factor 1 receptor gene. Am J Med Genet 1991;38:74-79.

21 Ho SC, Clayton P, Vasudevan P, Greening J, Wardhaugh B, Shaw N, Kelnar C, Kirk J, Hogler W: Recombinant human growth hormone therapy in children with chromosome 15q26 deletion. Horm Res Paediatr 2015;83: 424-430.

22 Rudaks LI, Nicholl JK, Bratkovic D, Barnett CP: Short stature due to $15 \mathrm{q} 26$ microdeletion involving IGF1R: report of an additional case and review of the literature. Am J Med Genet A 2011;155A:3139-3143.

23 Clementi M, Milani S, Mammi I, Boni S, Monciotti C, Tenconi R: Neurofibromatosis type 1 growth charts. Am J Med Genet 1999; 87:317-323.

24 van Duyvenvoorde HA, Lui JC, Kant SG, Oostdijk W, Gijsbers AC, Hoffer MJ, Karperien M, Walenkamp MJ, Noordam C, Voorhoeve PG, Mericq V, Pereira AM, Claahsen-van de Grinten HL, van Gool SA, Breuning $\mathrm{MH}$, Losekoot M, Baron J, Ruivenkamp CA, Wit JM: Copy number variants in patients with short stature. Eur J Hum Genet 2014;22:602-609.

25 Zahnleiter D, Uebe S, Ekici AB, Hoyer J, Wiesener A, Wieczorek D, Kunstmann E, Reis A, Doerr HG, Rauch A, Thiel CT: Rare copy number variants are a common cause of short stature. PLoS Genet 2013;9:e1003365.
26 Dauber A, Yu Y, Turchin MC, Chiang CW, Meng YA, Demerath EW, Patel SR, Rich SS, Rotter JI, Schreiner PJ, Wilson JG, Shen Y, Wu BL, Hirschhorn JN: Genome-wide association of copy-number variation reveals an association between short stature and the presence of low-frequency genomic deletions. Am J Hum Genet 2011;89:751-759.

$\checkmark 27$ Veenma DC, Eussen HJ, Govaerts LC, de Kort SW, Odink RJ, Wouters CH, Hokken-Koelega AC, de Klein A: Phenotype-genotype correlation in a familial IGF1R microdeletion case. J Med Genet 2010;47:492-498.

28 Miyatake S, Koshimizu E, Fujita A, Fukai R, Imagawa E, Ohba C, Kuki I, Nukui M, Araki A, Makita Y, Ogata T, Nakashima M, Tsurusaki Y, Miyake N, Saitsu H, Matsumoto N: Detecting copy-number variations in wholeexome sequencing data using the eXome Hidden Markov Model: an 'exome-first' approach. J Hum Genet 2015;60:175-182.

29 Glessner JT, Bick AG, Ito K, Homsy JG, Rodriguez-Murillo L, Fromer M, Mazaika E, Vardarajan B, Italia M, Leipzig J, DePalma SR, Golhar R, Sanders SJ, Yamrom B, Ronemus M, Iossifov I, Willsey AJ, State MW, Kaltman JR, White PS, Shen Y, Warburton D, Brueckner M, Seidman C, Goldmuntz E, Gelb BD, Lifton R, Seidman J, Hakonarson H, Chung WK: Increased frequency of de novo copy number variants in congenital heart disease by integrative analysis of single nucleotide polymorphism array and exome sequence data. Circ Res 2014;115:884-896.

-30 Samarakoon PS, Sorte HS, Kristiansen BE, Skodje T, Sheng Y, Tjonnfjord GE, Stadheim B, Stray-Pedersen A, Rodningen OK, Lyle R: Identification of copy number variants from exome sequence data. BMC Genomics 2014; 15:661. 